\title{
SANTO DOMINGO DE GUZMÁN Y SU VISIÓN DEL ESTUDIO
}

\author{
Santo Domingo de Guzmán and his Vision of the Study
}

Claudio Raúl Condori Cutimbo*

Recepción: 22-10-2018

Aceptación: 30-10-2018

\begin{abstract}
RESUMEN
El presente artículo es una reflexión sobre la obra de Santo Domingo de Guzmán, en particular sobre la importancia que tiene el estudio para la Orden de los Predicadores y para el ser humano que desea dar testimonio de su ser creyente, que, a su vez, es un medio válido para la evangelización y la presentación de la Verdad, que es el mismo Jesucristo.
\end{abstract}

Se trata de rescatar algunos elementos propios del sentido del estudio para la Orden de Predicadores y para ello será imprescindible conocer brevemente el contexto en que se sitúa dicho Santo, y las características propias del estudio. Finalmente es importante conocer los aportes que realiza la Orden de Predicadores para la cultura y el desarrollo de la ciencia y la investigación en el Perú, con la creación de diferentes centros superiores y universidades, hasta nuestros días.

\section{Palabras clave}

Estudio, Verdad. Evangelio, contemplación, predicación, experiencia intelectual, contexto.

\begin{abstract}
This paper reflects on the work of Saint Domingo de Guzmán, in particular the importance of study as a means for evangelization and the presentation of Truth, which is Jesus Christ himself. It aims to rescue some elements of the meaning of study for the Order of Preachers. To this end, it will be essential to know the context in which Saint Domingo de Guzmán is situated as well as the characteristics of his vision of study. Finally, it is important to know the contributions made, even to this day, by the Order of Preachers, to the culture and development of science and research in Peru by means of the establishment of numerous colleges and universities.
\end{abstract}

\section{Keywords:}

Study, truth, gospel, contemplation, preaching, intellectual experience, context.

* Docente de la Universidad Femenina Sagrado Corazón: claudiocondoric@unife.pe 


\section{Introducción}

El presente artículo tiene como objeto redescubrir la riqueza y la vigencia del pensamiento de Santo Domingo de Guzmán y la obra de la Orden de los Predicadores, respecto al sentido que se tiene sobre el estudio, que no es otra cosa que la búsqueda incesante de la verdad, con el aporte de todas las ciencias, en especial de la filosofía y la teología.

Decimos vigencia en cuanto que en esta época que nos toca vivir, se percibe un cierto deseo por lo relativo, por lo superfluo o vivir las situaciones momentáneas y pasajeras, situación no tan ajena a la realidad que tuvo que enfrentar Santo Domingo de Guzmán, por lo que insiste que uno de los caminos más adecuados para realizar la evangelización es la preparación intelectual, en cuanto que se tendrá que polemizar con diferentes corrientes de pensamiento, donde no siempre aceptan a Jesucristo como la plena Verdad y también recordando las palabras de San Pablo, que nos indica que debemos dar razón de nuestra fe.

Es preciso reconocer el aporte que realizaron los dominicos a favor de la evangelización de las culturas, haciendo que el evangelio ingrese en cada una de ellas, más aún el aporte a la cultura y la formación intelectual y científica de nuestro Perú con la creación de centros de estudios superiores y universitarios. Así los dominicos no quedaron pasivos a los cambios de las culturas y las épocas, sino todo lo contrario, aportaron al desarrollo de nuestras sociedades con la evangelización, la ciencia y la cultura, más aún el haber celebrado 800 años (1217) de fundación de la Orden de los Predicadores, más conocida como los dominicos, y de ser enviados a predicar la buena Nueva.

\section{Datos importantes de Santo Domingo de Guzmán}

Nació en Caleruega (Burgos) en 1170. Sus padres fueron, don Félix de Guzmán y doña Juana de Aza, parientes de reyes castellanos y de León, Aragón, Navarra y Portugal, descendían de los condes-fundadores de Castilla. Tuvo dos hermanos, Antonio y Manés.

Durante siete años fue educado por su tío el Arcipreste don Gonzalo de Aza, hasta los catorce años en que fue a vivir a Palencia: estudiaba los cursos de Artes, Filosofía y Teología. Al terminar la carrera de Artes en 1190, recibida la tonsura, se hizo Canónigo Regular en la Catedral de Osma. Fue en el año 1191, ya en Palencia, cuando en un rasgo de caridad heroica vende sus libros, para aliviar a los pobres del hambre que asolaba España.

En 1205, por encargo del Rey Alfonso VIII de Castilla, acompaña al Obispo de Osma, Diego, como embajador extraordinario para concertar en la corte danesa las bodas del príncipe Fernando. Con este motivo, tuvo que hacer nuevos viajes, y en sus idas y venidas a través de Francia, conoció los estragos que producían las herejías albigenses y cátaros. También se da cuenta de la ignorancia religiosa existente en la sociedad y entre los clérigos.

En 1215 asiste al Concilio de Letrán donde solicita la aprobación de su Orden. Será un año después, el 22 de diciembre de 1216, cuando reciba del Papa Honorio III la Bula "Religiosam Vitam" por la que confirma la Orden de Frailes Predicadores.

Con su Orden perfectamente estructurada y más de sesenta comunidades en funcionamiento, agotado físicamente, tras una breve enfermedad, murió el 6 de agosto de 1221, a los cincuenta y un 
años de edad, en el convento de Bolonia, donde sus restos permanecen sepultados. En 1234, el Papa Gregorio IX, lo canonizó. (Villacorta, 1998, pp. 45-60).

\section{Contexto de Santo Domingo de Guzmán.}

En primer lugar, se hace necesario tomar en cuenta el contexto en el que se desarrollaron las personas y la época en que vivieron, que dieron lugar al pensar y obrar de una u otra manera, por ello será útil tomar en cuenta el medio en el que surge la figura de Santo Domingo de Guzmán.

Para comprender a Santo Domingo de Guzmán Garcés, se debe empezar diciendo que se trata de un hombre que vivió a fines del siglo XII y los inicios del siglo XIII.

Era la época en que se iba cerrando la Edad Media, con la consiguiente pérdida de predominio de la Iglesia católica que se había vuelto un Estado con poder político, militar, económico e ideológico unido a su hegemonía religiosa. Era también el tiempo en que Europa iba dejando atrás el feudalismo con su economía básicamente agraria para pasar a la consolidación de la Ciudad-Estado que entronizaba a los reyes, que consolidaba el comercio y la pequeña producción industrial, mayormente textil.

No está demás mencionar que el papado había impulsado ya tres de las cinco guerras llamadas Cruzadas cuya finalidad era retomar el control de Jerusalén y los lugares santos que estaban en poder de los musulmanes. A Domingo de Guzmán le toco ver de cerca la Tercera Cruzada, llamada también "la cruzada de los reyes". Convocada por Gregorio VIII y continuada por Clemente III que movilizó a miles de soldados y a los principales reyes de Europa. El enfrentamiento final fue entre el rey de Inglaterra Ricardo Corazón de León y Saladino sultán de Siria y Egipto. Como ninguno pudo vencer totalmente al contrincante, en setiembre de 1192 firmaron un tratado por el cual Jerusalén permanecía bajo control musulmán, permitiendo a los peregrinos cristianos visitar la ciudad.

Esta situación de guerra arruinó la economía de Europa, no solo por el costo que tuvieron esas incursiones militares, sino porque, al enrolar en los ejércitos a la población joven, la fuerza laboral sufrió una fuerte baja con el consiguiente abandono de las artes y oficios menores, la caída de la producción agrícola y alimentaria trayendo empobrecimiento y hambre a la población en general. Los gobernantes recurrieron a los impuestos, diezmos, indulgencias y contribuciones para afrontar la situación económica haciendo aún más crítica la condición del poblador europeo. (Castillo, 2017, pp. 4-6).

No olvidemos que habiendo tenido una presencia muy fuerte durante toda la edad media (8 siglos), la Iglesia terminó siendo autoridad sobre asuntos espirituales y políticos, fue un poder económico dadas las muchas propiedades y bienes que ostentaba y porque sus miembros eran los más versados en asuntos de filosofía, teología, derecho, artes, historia, lectura y escritura; llegando casi a alejarse de su misión original y primigenia que era la caridad y el amor al prójimo.

Ante esta situación, Domingo de Guzmán no tomó la ruta de la sola crítica y denuncia de lo que estaba mal en la iglesia de Jesús, como más tarde sí lo hizo Lutero, sino que quiso encarnar aquello que quería ver en la Iglesia, por lo que renunció no solo a su herencia y patrimonio familiar, sino que se dio al trabajo de ir por los caminos del viejo mundo, como orden mendicante, a pie, 
anunciando el evangelio y dando ejemplo de pobreza y servicio al hambriento y necesitado.

Fue en esa tarea que se confrontó con la secta más activa y extendida llamada de los albigenses o cátaros cuya doctrina afirmaba que en el mundo había dos poderes y señores que se confrontaban por ganarse al ser humano. Una era Jesús, Dios del bien, que habitaba y atendía a las necesidades del espíritu con miras a su salvación y la otra era un ser malo demoníaco que habitaba el cuerpo del hombre y trataba de atender sus apetencias materiales, era el que lo arrastraba al pecado cuya sanción era el infierno.

Así en una oportunidad, Domingo de Guzmán conversaba con el dueño de una posaba, un albigense quien argumentaba lo peligroso que era el cuerpo para la salvación. Sin inmutarse Domingo le preguntó: Dime hermano, ¿Y entonces, por qué Jesús se ha encarnado?, ¿por qué siendo un Dios bueno ha elegido el cuerpo para anunciar el reino y predicar la salvación? El mesonero, al no tener respuesta dijo que lo iba a pensar. Domingo afirmaba que lo del bien y del mal estaba en el ejercicio de la libertad humana. (Vicaire, 1958, p. 73).

Convencido que su tarea era la predicación, a diferencia de los emisarios pontificios y demás predicadores que se hacían transportar en carruajes e iban acompañados de gendarmes para su protección, Domingo caminaba a pie, muchas veces solo y sin mochila predicando el evangelio del amor, la caridad, la compasión y el servicio al hermano, hijo de Dios.

Fue en eso que coincidió con Francisco de Asís, otro joven que no se acomodó a su tiempo ni a las riquezas de su familia. Muy por el contrario, renunció y se despojó de todo eso, dedicando su vida a predicar la hermandad, el perdón, la caridad y la oración a Dios Padre, Creador y dador de bienes. Ambos apuntalaron una Iglesia que había perdido el sentido de su misión original y, con mucha humildad y testimonio personal, hicieron de la iglesia una comunidad capaz de transmitir paz, esperanza y amor.

Como la predicación era su labor principal, pronto empezaron a desarrollar una pedagogía propia que a la vez que transmitía la doctrina cristiana fuera medio para esclarecer y convocar. Entonces, se dio paso a la escolástica convirtiendo a las iglesias y catedrales en centros de enseñanza sistematizada y organizada con el Trívium (gramática, retórica y dialéctica o lógica) y el Quadrivium (aritmética, astronomía, geometría y música). Siete artes liberales que introducían al ser humano en el buen uso de la palabra primero y luego en el conocimiento del mundo, al que se añadió la filosofía y la teología en las escuelas y posteriores universidades.

Más adelante es la Orden de los Predicadores, más conocidos como los dominicos quienes formularon mejor el sentido y la importancia del estudio y la enseñanza. Los dominicos fueron los que más se esforzaron en dotar a la educación de elementos científicos y filosóficos capaces de responder a las inquietudes ciudadanas y a las herejías reinantes. Fue tan relevante su labor que cuando el joven Tomás de Aquino decidió hacerse fraile, no tuvo mayor problema al elegir a los dominicos para su formación sacerdotal y su producción filosófica y teológica. (García, - Llorcas, 1958, pp. 803-805)

\section{Comprensión del estudio}

La originalidad de Santo Domingo de Guzmán consistió en colocar el 
estudio al servicio de la predicación, en dar a éste una significación y una finalidad específicamente apostólicas, es decir que el estudio era un instrumento para presentar a Jesucristo de manera coherente, evitando caer en las herejías que por entonces abundaban.

Cuando Santo Domingo de Guzmán afirma que es necesario presentar la Verdad, no hace referencia a la verdad filosófica, ni científica, sino la verdad desde la Teología que va a ser identificada con Jesucristo, dado que en esta etapa de la edad media en que se desarrolla Santo Domingo de Guzmán existe una gran inconsistencia en la comprensión de las verdades de fe y grandes errores sobre Jesucristo. Esta realidad le mueve al Santo a formar intelectualmente a sus Frailes para que sepan defender y presentar el Evangelio. Su intuición profética consistió en darse cuenta de la absoluta necesidad de una adecuada preparación intelectual para la renovación efectiva del ministerio de la predicación y de hacer vida las palabras del gran Apóstol Pablo de Tarso, tenemos que saber dar razón de nuestra fe. Desde los orígenes los dominicos tienen algunos componentes fundamentales para la predicación como son; la vida fraterna, la oración, y el estudio; sin embargo, es el estudio quien tiene desde el principio la finalidad de ser instrumento para presentar las verdades de fe y así lograr la salvación de las almas.

En la edad media existían dos corrientes respecto al estudio y a la enseñanza: la Escuela de los Místicos (el ideal de esta escuela coloca su énfasis en la experiencia mística) y la Escuela de los Maestros (su propósito apostólico y misionero es iluminar al hombre secular en sus propias circunstancias históricas). Estas tienen una concepción distinta y hasta contrapuesta del estudio y de la tarea intelectual.
Domingo se inspira en la Escuela de los Maestros y en ella encuentra el verdadero sentido y finalidad del estudio. Siguiendo la tradición de los Maestros, pone el estudio al servicio de su proyecto apostólico y de la búsqueda permanente de la verdad. (Guy, 1996, p. 47).

El estudio es un componente esencial del proyecto de la Orden de los Predicadores, es por ello que no se concibe un verdadero Predicador, si no se dedica al mismo tiempo a la contemplación de la realidad y al estudio de la verdad sagrada. Un estudio sin finalidad apostólica perdería su carácter dominicano, por ello que Santo Tomás enfatizó el carácter esforzado y ascético de la activad intelectual, y nos dirá que el "Estudio es una palabra que designa aplicación intensa de la mente a algo, cosa que no puede hacerse sino mediante su conocimiento". (citado por Clerissac, 2013, p. 22). Coloca el estudio entre las partes de la templanza, y distingue en ella dos aspectos: el apetito de saber y el esfuerzo requerido por la actividad intelectual. Es una tarea esforzada y ascética que requiere laboriosidad, paciencia y constancia para predicar desde la verdad.

Más aun el estudio dominicano tendrá un carácter teológico y filosófico; teológico porque se centrará en el estudio de la verdad sagrada para ser anunciada y predicada. Filosófico porque ayudará a comprender la condición humana y nuestro lugar en el cosmos.

Así, esta relación que realizan los dominicos entre teología y filosofía es válida para nuestro tiempo puesto que la predicación o el anuncio del Evangelio requiere estar atento a los nuevos conocimientos y a las nuevas maneras de entender el mundo que nos rodea. Porque Dios revela su plan en una multitud de maneras, de ahí la importancia 
de mantener esa tensión entre la filosofía y la teología, tal como nos recordará San Juan Pablo II en la encíclica Fides et Ratio:

Privada de lo que la revelación ofrece, la razón ha tomado caminos irrelevantes que la exponen al peligro de perder de vista su meta final. Privada de la razón, la fe ha enfatizado el sentimiento y la experiencia, y por lo tanto corre el riesgo de no poder ya ser una propuesta universal. Es una ilusión pensar que la fe unida a un razonamiento pobre podría ser más penetrante; al contrario, la fe corre entonces el riesgo de atrofiarse en mito o en superstición. Por lo mismo, la razón que no está relacionada con una fe madura no es llamada a dirigir su mirada a la novedad y radicalidad del ser (Fides et Ratio,48).

De este modo podemos caracterizar dos rasgos importantes en la comprensión del estudio, que de alguna manera definirán la trayectoria histórica y espiritual de la Orden de Predicadores; dos rasgos que se encuentran como lemas entre los dominicos: VERITAS, es decir, Verdad, y 'contemplata aliis tradere', traducida por, contemplar y dar lo contemplado.

\section{Primer rasgo: Veritas}

Las Instituciones religiosas o civiles, sobre todo aquellas que provienen de la Edad media, traen emblemas, símbolos, escudos que las identifican; los dominicos no son ajenos a esta realidad, es por ello que encontramos su lema: VERITAS, es decir, Verdad. Así el ideal de los dominicos ha sido definido en reiteradas ocasiones como el ideal de la Verdad.

Sin embargo, en palabras de fr. Guibert de Tournai, podemos decir que: nunca descubriremos la Verdad si nos contentamos con lo descubierto... Los escritores que nos precedieron no son nuestros señores, sino nuestros guías. La Verdad está abierta a todos; aún no ha sido ocupada. (Jordán de Sajonia, 1998, p. 7).

Con esta afirmación se quiere poner de manifiesto que la Verdad no es monopolio de nadie, además, antes de que surgieran los dominicos, en el siglo XIII, existía esta expresión para denominar a otros grupos sociales y eclesiales de manera que la búsqueda de la Verdad es un proyecto y un ideal para cualquier ser humano, entonces nos preguntamos ¿Quién no añora explorar la Verdad que se encierra en sí mismo, en la naturaleza, en los acontecimientos que tienen lugar? Con el lema VERITAS, los dominicos no hacen más que recordar un ideal para toda persona. Porque no debemos olvidar una convicción: fuera de la Verdad todo se construye en falso. Debemos llegar a los hombres en su deseo de Verdad. Así los dominicos intentaron contactar con los hombres en su búsqueda de la Verdad. Es decir, se quiso relacionar con los hombres y mujeres de cada tiempo en su aspiración a conocer las cosas tal como son, a comprenderlas y a difundirlas. Lo que caracterizó siempre al máximo la mentalidad dominicana es el sentido de la Verdad de las cosas, que evidentemente no puede separarse la Verdad del hombre y la Verdad de Dios, este estilo dominicano también debe aparecer en nuestra manera de abordar los problemas y de aclarar las soluciones. Buscar en todo momento la verdad, aún que no nos pareciera.

De esta manera el ideal de la Verdad se presenta de manera sublime, pero también es fácilmente sublimable. Por eso conviene mantenerse fieles a la tierra y a la historia, para no caer en falsos idealismos. La Verdad es la realidad misma, por ello fr. Vicente de Couesnongle pedía a los dominicos tener 
un sexto sentido: el sentido de la Verdad objetiva, la Verdad de las cosas, que nos sitúa a igual distancia de la mistificación y de la moralización. La Verdad de las cosas es más real y objetiva que todas las sublimaciones y mistificaciones a las que con frecuencia sometemos la realidad. La Verdad de las cosas, del hombre y de Dios, es más consistente que todas las moralizaciones que con frecuencia inspiran los discursos evangelizadores. (Clerissac, OP, 2013, pp.25-26)

Este ideal de la Verdad, retomado por la Orden de Predicadores, permitió poner de manifiesto en dicha Institución religiosa la importancia esencial que tiene el estudio en el proyecto dominicano. El estudio, entendido como búsqueda constante de la Verdad absoluta, y es por ello que la Orden de los Predicadores asumen el título de la Orden de la Verdad.

\section{Segundo rasgo: la actividad contemplativa}

Hablar de la actividad contemplativa dominicana, en la dinámica del estudio, fue siempre realizar la conexión entre la vida espiritual y las principales aspiraciones y necesidades del ser humano, por ello que un autor dominico insistía en que la contemplación dominicana no tenía ni tiene el sentido de mera inquietud y acallamiento, al estilo de las grandes órdenes contemplativas por excelencia; para el dominico contemplar es dejar abierta la vía del intercambio; es llevar a su reflexión los afanes del ser humano y de devolver con un efecto de bendición y divinización las respuestas, las oscuridades o los interrogantes, iluminados por la luz y el calor de Dios. No siempre tendremos respuestas a nuestras interrogantes, pero sí podremos mantener nuestras inquietudes y perplejidades para buscar la verdad de modo que vivir en la contemplación, al estilo dominicano, siempre generó personas de encuentro.

Encuentro entre Dios y los hombres y encuentro de los hombres entre sí. Por eso la contemplación dominicana intentó ser una "teología de Dios para los hombres" y una "antropología del hombre para Dios como nos recordará Fray Jordán de Sajonia. (Jordán de Sajonia, OP, 1998, p.20).

Así reflexionando, Santo Tomás de Aquino afirmó que la vocación de todo dominico debe ser contemplar y dar lo contemplado (Jordán de Sajonia, OP 1998, p.27). Es una sabiduría tal que nos habla no sólo de lo eterno, sino también de la misma realidad donde el hombre se desarrolla. Pertenece al don de la sabiduría no sólo meditar en Dios sino también dirigir las acciones humanas. El estudio sapiencial se despliega necesariamente como compasión intelectual: una forma de compasión que presupone la comprensión intelectual obtenida o desarrollada por el estudio; y una forma de comprensión que lleva a la compasión. "Puesto que, así como es mejor iluminar que sólo brillar, también es mejor dar a otros los frutos de la propia contemplación que solamente contemplar" (Cuadros, 2016, p. 115).

Entonces, aunque la misericordia y compasión de Dios llegan al mundo en una multitud de modos, por el carisma dominicano llegan a través del estudio y la búsqueda por la verdad.

En las constituciones de la orden de los Predicadores se señala esta dimensión contemplativa del estudio como una meditación de la multiforme sabiduría de Dios, es decir que dedicarse al estudio es responder a una llamada a "cultivar la búsqueda humana de la verdad" (Jordán de Sajonia, OP, 1998, p.44). Puede decirse que la Orden nace 
de este amor por la verdad y de esta convicción de que los seres humanos son capaces de conocer la verdad. De modo que, desde el comienzo, los discípulos de Santo Domingo son inspirados por su audacia innovadora que los alentó a ser útiles a las almas por la compasión intelectual, al compartir con ellos la misericordia de la verdad. Jordán de Sajonia dice que Santo Domingo tenía la habilidad de penetrar hasta el núcleo oculto de muchas cuestiones difíciles de aquellos días gracias a "una humilde inteligencia del corazón" (Clerissac, 2013, p. 9).

El estudio está así unido a esa misericordia que nos mueve a proclamar el Evangelio del amor de Dios al mundo y la dignidad que resulta de tal amor. El estudio ayudará a percibir las crisis, necesidades, anhelos y sufrimientos ajenos como propios.

\section{Los dominicos y el estudio hoy}

Entender el estudio bajo las dos perspectivas mencionadas, nos lleva a afirmar que la misión intelectual en la Orden de los Predicadores los llama a compartir no sólo los gozos y las esperanzas, sino también las oscuridades y las lágrimas que tiene el hombre de nuestro tiempo como nos recordará el documento del Concilio Vaticano II:

los gozos y las esperanzas, las tristezas y las angustias de la gente de nuestro tiempo, sobre todo de los pobres, y de cuantos sufren, son a la vez gozos y esperanzas, tristezas y angustias de los discípulos de Cristo. Nada hay verdaderamente humano que no encuentre eco en su corazón. La comunidad cristiana está integrada por gente, que, reunida en Cristo, es guiada por el Espíritu Santo en su peregrinar hacia el Reino del Padre y ha recibido la buena nueva de salvación para comunicarla a todos. La iglesia, por ello, se siente íntima y realmente solidaria del género humano y de su historia" (Gaudium et Spes 1).

Aunque en nuestro tiempo el desarrollo histórico se presenta de manera ambivalente por las múltiples contradicciones o paradojas que vive el ser humano, sin embargo, desde la compasión intelectual que consiste en hacer suyo, de manera consciente, lo que la realidad presenta y desde esa perspectiva buscar respuestas a las grandes preguntas que el hombre se fomula y que desea encontrar la verdad sobre si mismo y sobre la realidad, es entonces donde el amor por el estudio adquiere importancia para lo que el hombre busca: la verdad.

\section{Aporte de los dominicos a la cultura peruana}

La Universidad Nacional Mayor de San Marcos, Decana de América, fue fundada el 12 de mayo de 1551, fue el inicio de la historia universitaria del continente. Los dominicos fueron los propulsores de esta casa de estudios quienes, desde el año de 1548 con Fray Tomás de San Martín, toman el interés de este proyecto para la formación de sus novicios y de sus frailes.

La iniciativa eclesiástica fue acogida y recibió un poderoso impulso laico del cabildo limeño. Se nombraron dos procesadores, civil y eclesiástico, los que al término de una feliz gestión determinaron la fundación de la Universidad.

Esta fue hecha por Real Cédula firmada por el rey Carlos V en la ciudad de 
Valladolid, el 12 de mayo de 1551, y llevó por nombre Universidad de Lima. Es a partir de 1574 que toma el de Universidad de San Marcos.

La Universidad inició sus funciones el 2 de enero de 1553 en la sala capitular del Convento del Rosario de la Orden de los Dominicos, con la concurrencia de la Real Audiencia presidida por el licenciado Andrés Cianca y el enviado de la Corona Cosme Carrillo, primer miembro laico del cuerpo docente.

Durante la época virreinal las Facultades fueron cinco. En el período republicano, hasta 1969 llegaron a diez. Al inaugurarse los estudios de la Universidad sus asignaturas iniciales correspondían a las Facultades de Teología y Arte que posteriormente se van abriendo otras facultades hasta el día de hoy que posee 62 carreras profesionales distribuidas en 20 facultades. (Álvarez, 1997, p. 335)

Otra universidad gestionada por los dominicos es la de San Martín de Porres, cuyos orígenes se remontan al Instituto Pro-Deo, una casa dedicada al cultivo de la filosofía y la teología, que fundara el RP Dr. Vicente Sánchez Valer, de la orden de los predicadores (dominicos). Poco después que el Papa Juan XXIII elevara a los altares al beato Fray Martín de Porres Velásquez, de la Orden Dominica del Perú, se funda la Universidad bajo la advocación del nuevo santo, el 17 de mayo de 1962. Las primeras facultades fueron las de Educación y Letras, incluyendo los Institutos de Filosofía, Castellano, Leteratura, Historia, Geografía y Periodismo. El Primer rector fue el fundador, el RP Vicente Sánchez Valer (Álvarez, 1997, p. 356).

En la actualidad tenemos, con ese espíritu dominico del estudio, al RP Gustavo Gutiérrez, con su aporte a la
Iglesia universal y a la humanidad, desde la teología, con su reflexión y propuesta que se condensa en la Teología de la Liberación, que constituye un aporte a la comprensión teológica de la realidad desde América Latina.

\section{Conclusión}

Podemos afirmar primero que el fin de la Orden de Predicadores no fue crear intelectuales sino formar predicadores competentes y que sepan dar razón del anuncio del evangelio en todos los ambientes culturales posibles, por ello su preocupación constante de tener un clero preparado con las ciencias que se requerían para que el anuncio fuera eficaz, creíble y se propagara a través del conocimiento. Desde los primeros días de la fundación, la Orden de Predicadores ha promovido sin temor una espiritualidad de diálogo ante los desafíos que el mundo tiene y que aún nuestras sociedades contemporáneas necesitan.

Nos invita a valorar la investigación y el estudio para alcanzar la verdad en su plenitud.

Nos llama a asumir el estudio desde la contemplación para que de esta manera se pueda caminar hacia la verdad y dar solución a las grandes interrogantes que el hombre tiene.

La Orden de los Predicadores aportó a la evangelización de muchos lugares del mundo en especial de Latinoamérica y el Perú.

En el campo de la cultura, en el Perú favoreció la creación de centros de estudios superiores, primeramente, para sus frailes y posteriormente para todos los ciudadanos de estas tierras, con la creación del primer centro sistemático 
de estudios como es la fundación de la Universidad Nacional Mayor de San Marcos, Institutos Superiores de Educación, entre otros.

\section{Referencias bibliográficas}

Álvarez, G. (1997) Historia de la Orden dominicana en el Perú. Lima: Paulinas

Castillo, C (2017) Retrato de Domingo de Guzmán, Lima, Santa Anita

Cuadros, J. OP (2016) Un poco de Luz para nuestra fe. Lima: Fénix

Clerissac, H. OP, (2013) El Espíritu de Santo Domingo. Lima: Fénix

García, S. - Llorcas, B. (1958) História de la Iglesia Católica Tomo II. Madrid: BAC.
Guy, B. (1996) A imagen de Santo Domingo. Salamanca: San Esteban

Jordán de Sajonia, OP (1998). De principiis odinis praedicatorum. Lima

Juan Pablo II (1998) Carta encíclica Fides et Ratio. Lima: Salesiana.

Vaticano II (2008) Gaudium et spes. Lima: Paulinas

Vicaire, H. (1958) Santo Domingo. Bilbao: Belgas.

Villacorta, A. (1998) El castellano Domingo de Guzmán. Salamanca: San Esteban. 